\section{Successful Treatment with Infliximab of a Patient with Tumor Necrosis Factor-associated Periodic Syndrome (TRAPS) Who Failed to Respond to Etanercept}

\section{To the Editor:}

Tumor necrosis factor (TNF)-associated periodic syndrome (TRAPS) is an autosomal dominant autoinflammatory disorder, previously known as Hibernian fever ${ }^{1}$, renamed TRAPS following the elucidation of TNFRSF $1 A$ as the susceptibility gene ${ }^{2,3}$, with mutations occurring generally on chromosome $12 \mathrm{p} 13$. The condition is autoinflammatory as there is no involvement of antigen-specific T cells, pathogens, or antibody production. TRAPS is characterized by recurrent febrile attacks of $>1$ week duration, severe abdominal pain, myalgia, rash, conjunctivitis, headache, periorbital edema, and pleuritis ${ }^{4}$.

Treatment options for TRAPS have met with limited success. Nonsteroidal antiinflammatory drugs are beneficial in controlling fever, but not abdominal and musculoskeletal symptoms. Glucocorticoids, although effective for inflammatory symptoms, do not prevent future attacks and the use of escalating doses is limited by toxicity ${ }^{5}$. Anti-TNF agents have demonstrated variable efficacy ${ }^{5-14}$. We describe the case of a 48-year-old woman of Italian Catalonian descent with TRAPS who was treated successfully with infliximab.

At disease onset in 1994, our patient presented with fevers lasting 7-14 days with monthly periodicity, increasing to twice monthly 3 years later. With the attacks, she experienced recurrent migratory rashes that were tender, red, raised, papular, and nodular, and serpinginous and annular plaques over her body including face and trunk (Figures $1 \mathrm{~A}$ and 1B). She had recurrent oral ulcers, sore throat, arthralgias, arthritis with knee effusions, myalgias, pleuritic-like chest pain, abdominal pain, eye redness and swelling, and debilitating fatigue. In 1998, attacks became almost continuous, with only 7 days of symptom-free relief per month. She could no longer function at her occupation as a photography laboratory receptionist.

Acute-phase reactants were only modestly elevated during attacks
(Figure 2). Antinuclear antibodies, rheumatoid factor, antineutrophil cytoplasmic antibodies, VDRL, angiotensin-converting enzyme, anti-DNA antibodies, and C3 and C4 were not diagnostic.

Between 1994 and 1999, therapeutic trials of colchicine, methotrexate, azathioprine, and cyclosporine A were unsuccessful. Daily oral steroids (20 mg prednisone) attenuated the manifestations, but the "attacks" persisted.

A report in $1999^{11}$ prompted submission of our patient's serum for analysis to the US National Institutes of Health (NIH), Arthritis and Musculoskeletal and Skin Diseases Branch. A molecular diagnosis of TRAPS was confirmed with an R92Q-type mutation identified on the $12 \mathrm{p} 13$ chromosome of the TNFRSF1A gene.

The patient was 1 of 15 symptomatic patients enrolled in an NIH-sponsored open-label pilot study to evaluate the safety and efficacy of etanercept in TRAPS (no. 00-AR-0112) ${ }^{14}$. After a 12-week observation period, she received etanercept $25 \mathrm{mg}$ twice weekly for 12 weeks. She experienced reduction of fever, but still required moderate doses of prednisone to control other symptoms. Etanercept was increased to $25 \mathrm{mg} 3$ times weekly in the next phase, but her periodic attacks continued. Sixteen weeks into active treatment, she experienced chest pains and shortness of breath and withdrew from the study. In October 2000, she received infliximab at an induction regimen of $3 \mathrm{mg} / \mathrm{kg}$ at 0,2 , and 6 weeks, without significant response. Prednisone requirements averaged $25 \mathrm{mg} /$ day. When infliximab was increased to $5 \mathrm{mg} / \mathrm{kg}$ every 6 weeks, attacks became mild and the prednisone dose could be lowered to $5 \mathrm{mg}$ /day. Subsequent increases of infliximab to $7.5 \mathrm{mg} / \mathrm{kg}$ and then to $10 \mathrm{mg} / \mathrm{kg}$ every 4 weeks led to cessation of fever and associated symptoms, and permitted discontinuation of steroids (Figure 2).

Infliximab has dose-dependently normalized erythrocyte sedimentation rate and reduced glucocorticoid use by $90 \%$ from baseline. She now enjoys long attack-free periods (Figure 2). Infusions have been maintained on a monthly basis. Average doses of prednisone have not exceeded $5 \mathrm{mg} / \mathrm{day}$ for short intervals. Attempts at prolonging the infusion interval have been consistently associated with an increase in attack frequency and severity.

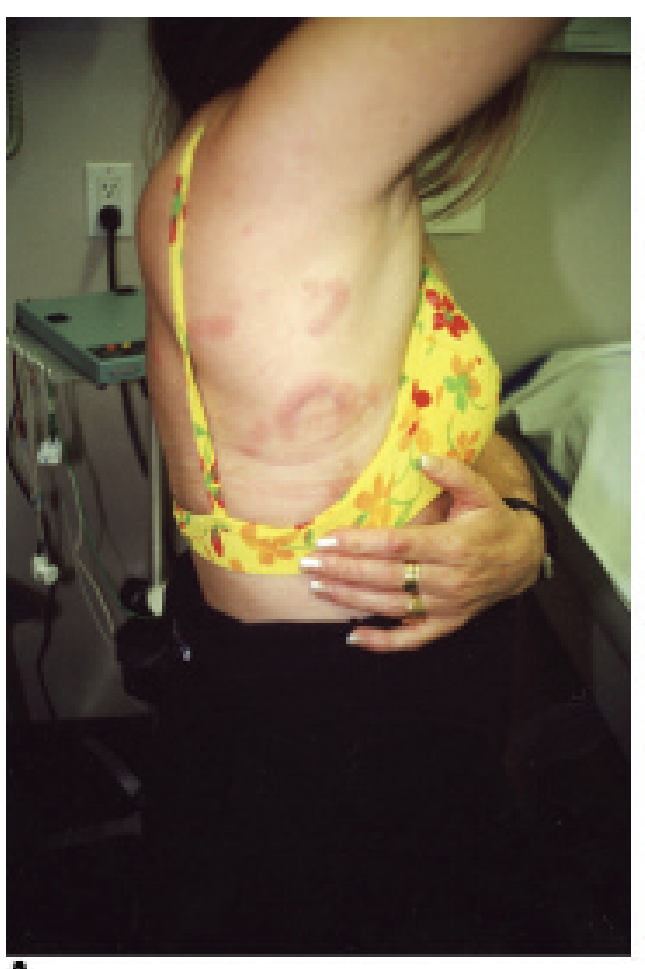

A

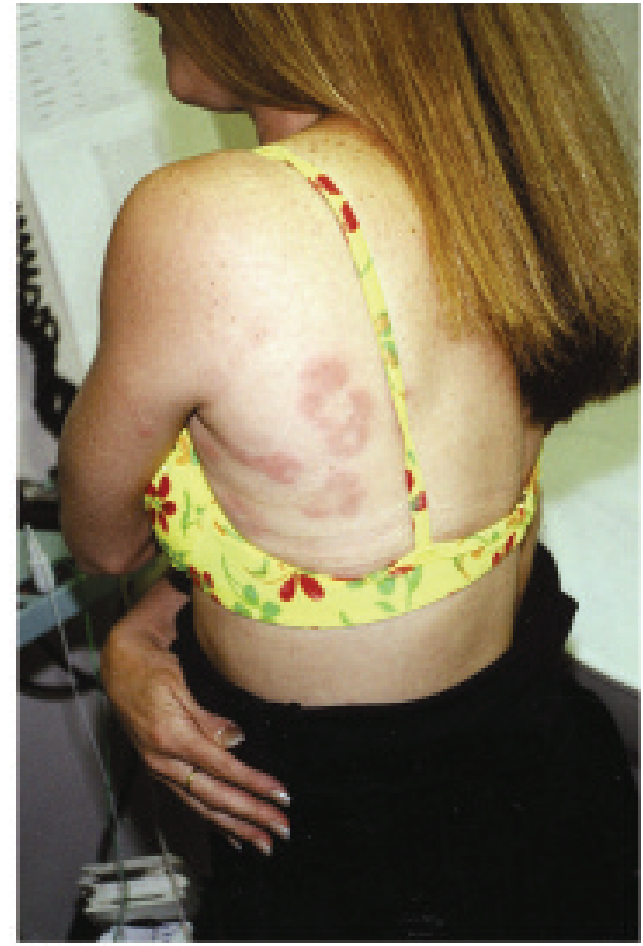

B

Figure 1. TRAPS-associated cutaneous lesions prior to treatment with infliximab (A, lateral view; B, posterior view).

Personal non-commercial use only. The Journal of Rheumatology Copyright @ 2010 . All rights reserved. 


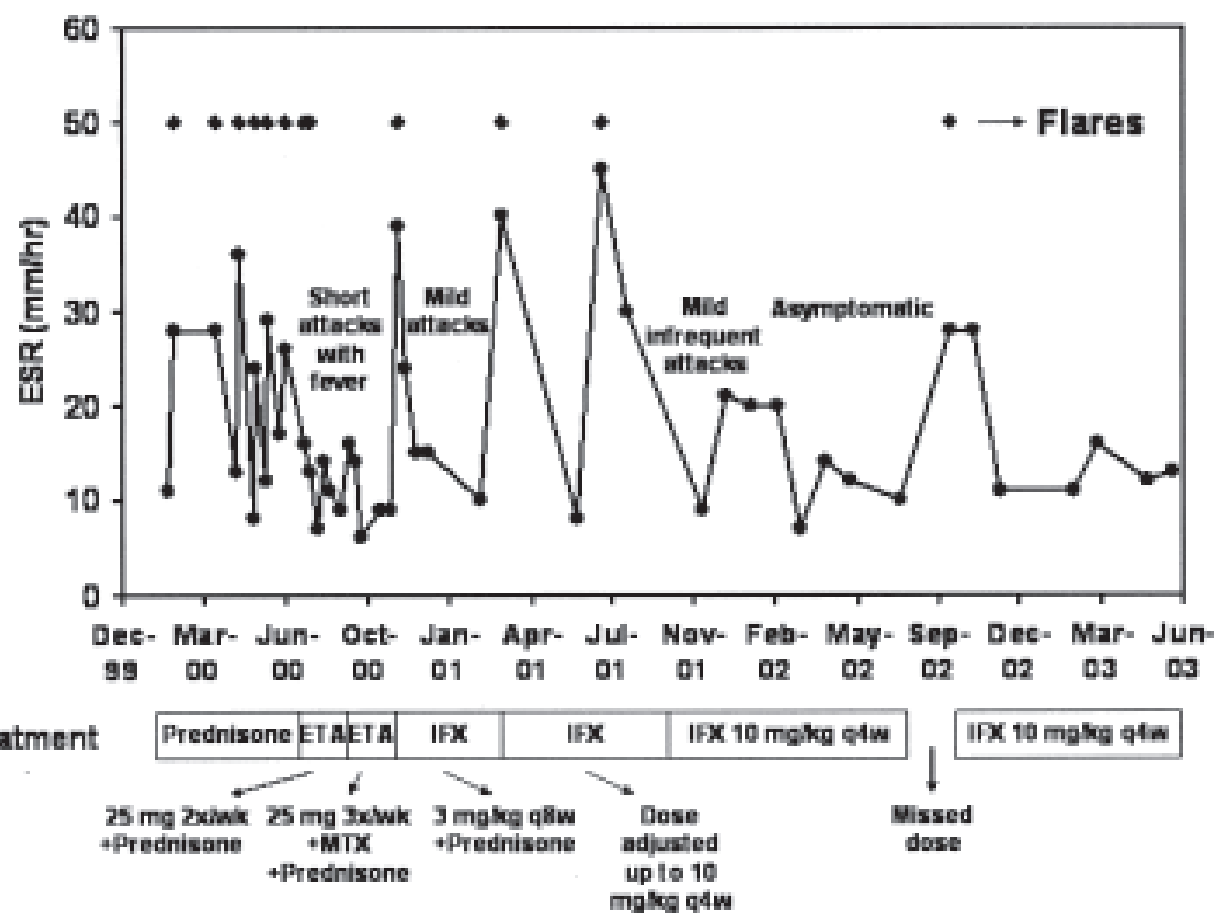

Figure 2. The patient's course: treatment response with clinical status and flares, and associated erythrocyte sedimentation rate (ESR) values. ETA: etanercept; IFX: infliximab; MTX: methotrexate.

She has experienced no adverse reactions related to infliximab, and no evidence of systemic amyloidosis. Acute-phase reactants have been maintained within normal limits. We are monitoring this patient closely to assess the longterm safety and efficacy of therapy. This is the first reported case of successful treatment of TRAPS with infliximab.

Several studies have suggested that R92Q is a low-penetrance mutation rather than a benign polymorphism ${ }^{15,16}$ based on its increased frequency among patients with periodic fever versus controls (3.3\% vs $1.04 \%$, respectively; $p=0.02$ ) and results of functional receptor studies ${ }^{15}$. Serum samples from R92Q patients taken during and between febrile attacks revealed that levels of the soluble p55 TNFRSF1A did not increase during the attack, suggesting the presence of an in vivo functional abnormality ${ }^{15}$. Our patient may be one of the few symptomatic individuals bearing this low-penetrance mutation ${ }^{2,15,16}$. Recent evidence of increased frequency of R92Q in other inflammatory disorders such as early rheumatoid arthritis ${ }^{17}$ and Behçet's disease ${ }^{18}$ suggest R92Q may also be a nonspecific factor in other inflammatory diseases.

Mixed results were achieved in a series of uncontrolled clinical trials with etanercept involving 30 patients with TRAPS ${ }^{5-11}$. In several cases, the good initial response waned over time ${ }^{10}$. Both regression and emergence of new cases of amyloidosis are reported ${ }^{7,12}$. Four patients ${ }^{9,10,13}$ treated with infliximab experienced a paradoxical acute flare within 12 hours of administration; 2 had previously received etanercept that had been discontinued due to a waning response. One of these had been involved in a 24 -week clinical trial of TRAPS, in which 7 patients received etanercept $25 \mathrm{mg}$ subcutaneously twice weekly ${ }^{5,10}$. After completing the study, the patient received a second 24-week treatment cycle, which was discontinued due to declining response. He experienced a flare similar to that with infliximab when subsequently treated with adalimumab ${ }^{13}$. The other 3 patients with flares associated with infliximab had been described in individual case reports ${ }^{9,13}$. Two patients responded favorably to anakinra after failing antiTNF agents ${ }^{19,20}$, suggesting that interleukin 1 may play a role in the pathogenesis.

Binding of TNF to cell-surface receptors yields a conformational change that induces a cellular signal leading to shedding of the extracellu- lar portion of the receptor from the cell surface. It then binds circulating $\mathrm{TNF}$, attenuating the inflammatory response. McDermott and coworkers demonstrated that TRAPS patients have reduced levels of soluble TNFRSF1A relative to controls, and suggested that the mutation mediated its effect by impairing the shedding of TNFRSF1 and reducing the quantity of soluble receptor available to bind TNF- $\alpha^{21}$. Other underlying mechanisms may be active ${ }^{2}$ including altered intracellular trafficking, impaired TNF binding ${ }^{22}$, and a defect in TNF-induced leukocyte apoptosis ${ }^{23}$. The efficacy of infliximab in controlling TRAPS could be explained in part by its capacity to form very stable complexes with both soluble TNF and membrane-bound TNF (tmTNF) ${ }^{24}$.

Infliximab can lyse TNF-producing cells by activation of complement ${ }^{23}$. The high avidity binding and capacity to crosslink tmTNF seen with infliximab could be a necessary condition to initiate the apoptotic cascade, which appears to be deficient in TRAPS and may be important for the induction of remission. In addition, the dimerization of tmTNF by infliximab could stimulate outside-in signal transduction, leading to apoptosis ${ }^{25}$.

Some investigators have suggested that whereas etanercept may have a beneficial but not sustainable effect in TRAPS, infliximab and possibly adalimumab may cause paradoxical inflammatory attacks ${ }^{9,10}$. Nedjai and coworkers ${ }^{26}$ reported that peripheral blood mononuclear cells from a family of TRAPS patients carrying the T50M mutation failed to respond to infliximab through apoptotic induction of capsase 3 activity, as compared to controls. These findings may, however, be limited to the T50M variant and not apply to the R92Q type identified in our patient, and not reflect her positive clinical outcome.

Our patient's excellent response to infliximab could be attributed to the higher $10 \mathrm{mg} / \mathrm{kg}$ dose that may have been required to prevent the flares experienced by patients treated with $5 \mathrm{mg} / \mathrm{kg}$. Higher-dose infliximab generated a favorable response in refractory childhood uveitis (10-20 $\mathrm{mg} / \mathrm{kg})^{27}$ and in dermatomyositis and polymyositis $(7-10 \mathrm{mg} / \mathrm{kg})^{28}$.

Given the documented heterogeneity of TRAPS and specifically of the R92Q variant ${ }^{2}$, our patient's condition may be a distinct variant from that of patients who did not respond or who experienced flare while receiving infliximab. 
Targeted therapies that block key cytokines have been remarkably effective in some patients with TRAPS. Work is required to identify patients that will benefit from available therapies and optimal dosing regimens. Elucidation of the underlying genetic and pathophysiologic mechanisms will guide development of treatment options for the multiple variants of this challenging condition.

MARILYN KRELENBAUM, MSc, Healthcare Consultant; ABRAHAM CHAITON, MD, MSc, FRCPC, Attending Staff Rheumatologist, Humber River Regional Hospital, Toronto, Ontario, Lions Gate Hospital, North Vancouver, British Columbia; Lecturer in Rheumatology, University of Toronto Department of Medicine, Division of Rheumatology, Sunnybrook Hospital Medical Centre, Toronto, Ontario, Canada. Address correspondence to Dr. Chaiton; E-mail: achaiton@aol.com

This report is dedicated to the late Dr. Adele Fam. He inspired and encouraged a commitment to excellence from everyone who crossed his path.

\section{REFERENCES}

1. Williamson LM, Hull D, Mehta R, Reeves WG, Robinson GH, Toghill PJ. Familial Hibernian fever. QJM 1982;51:469-80.

2. Hull KM, Drewe E, Aksentijevich I, Singh HK, Wong K, McDermott EM, et al. The TNF receptor-associated periodic syndrome (TRAPS): emerging concepts of an autoinflammatory disorder. Medicine 2002;81:349-68.

3. McDermott EM, Smillie DM, Powell RJ. Clinical spectrum of familial Hibernian fever: a 14-year follow-up study of the index case and extended family. Mayo Clin Proc 1997;72:806-17.

4. Padeh S, Berkun Y. Auto-inflammatory fever syndromes. Rheum Dis Clin North Am 2007;33:585-623.

5. Drewe E, McDermott EM, Powell PT, Isaacs JD, Powell RJ. Prospective study of anti-tumour necrosis factor receptor superfamily $1 \mathrm{~B}$ fusion protein and case study of anti-tumour necrosis receptor superfamily $1 \mathrm{~A}$ fusion protein, in tumour necrosis factor receptor associated periodic syndrome (TRAPS): clinical and laboratory findings in a series of seven patients. Rheumatology 2003;42:235-9.

6. Nigrovic PA, Sundel RP. Treatment of TRAPS with etanercept: use in pediatrics. Clin Exp Rheumatol 2001;19:484-5.

7. Drewe E, McDermott EM, Powell RJ. Treatment of the nephrotic syndrome with etanercept in patients with the tumor necrosis factor receptor-associated periodic syndrome. N Engl J Med 2000;343:1044-5.

8. Aróstegui JI, Solís P, Aldea A, Cantero T, Rius J, Bahíllo P, et al. Etanercept plus colchicine treatment in a child with tumour necrosis factor receptor-associated periodic syndrome abolishes auto-inflammatory episodes without normalising the subclinical acute phase response. Eur J Pediatr 2005;164:13-6.

9. Jacobelli S, André M, Alexandra J-F, Dodé C, Papo T. Failure of anti-TNF therapy in TNF receptor 1-associated periodic syndrome (TRAPS). Rheumatology 2007;46:1211-2.

10. Drewe E, Powell RJ, McDermott EM. Comment on: Failure of anti-TNF therapy in TNF receptor 1-associated periodic syndrome (TRAPS) [letter]. Rheumatology 2007;46:1865-6.

11. Kastner DL, Aksentijevich I, Galon J, McDermott MF, Ortmann R, Henrickson M, et al. TNFR1 mutations and early experience with etanercept therapy [abstract]. Arthritis Rheum 1999;42 Suppl:S117.

12. Drewe E, Huggins ML, Morgan AG, Cassidy MJ, Powell RJ. Treatment of renal amyloidosis with etanercept in tumour necrosis factor receptor-associated periodic syndrome. Rheumatology 2004;43:1405-8.

13. Church LD, Churchman SM, Hawkins PN, McDermott MF. Hereditary auto-inflammatory disorders and biologics. Springer Semin Immunopathol 2006;27:494-508.
14. Hull KM, Dean JA, Singh H, O'Shea JJ, Kastner DL. Efficacy of etanercept in TNF-receptor associated periodic fever syndrome (TRAPS): Results from an ongoing clinical trial [abstract]. Arthritis Rheum 2001;44:2948.

15. Aksentijevich I, Galon J, Soares M, Mansfiel E, Hull K, Oh H-H, et al. The tumor-necrosis-factor receptor-associated periodic syndrome: New mutations in TNFRS1A, ancestral origins, genotype-phenotype studies, and evidence for further genetic heterogeneity of periodic fevers. Am J Hum Genet 2001;69:301-14.

16. Ravet N, Rouaghe S, Dodé C, Bienvenu J, Stirnemann J, Lévy P, et al. Clinical significance of P46L and R92Q substitutions in the tumour necrosis factor superfamily $1 \mathrm{~A}$ gene. Ann Rheum Dis 2006;65:1158-62.

17. Jawaheer D, Seldin MF, Amos CI, Chen WV, Shigeta R, Monteiro $\mathrm{J}$, et al. A genome-wide screen in multiplex rheumatoid arthritis families suggests genetic overlap with other autoimmune diseases. Am J Hum Genet 2001;68:927-36.

18. Amoura Z, Dode C, Hue S, Caillat-Zucman S, Bahram S, Delpech $\mathrm{M}$, et al. Association of R92Q TNFRS1A mutation and extracranial deep vein thrombosis in patients with Behçet's disease. Arthritis Rheum 2005;52:608-11.

19. Simon A, Bodar EJ, van der Hilst JC, van der Meer JW, Fiselier TJ, Cuppen MP, et al. Beneficial response to interleukin I receptor antagonist in TRAPS. Am J Med 2004;117:208-10.

20. Sacré K, Brihaye B, Lidove O, Papo T. Dramatic improvement following interleukin $1 \beta$ blockade in tumor necrosis factor receptor- 1 associated syndrome (TRAPS) resistant to anti-TNF- $\alpha$ therapy. J Rheumatol 2008;35:357-8.

21. McDermott MF, Aksentijevich I, Galon J, McDermott EM, Ogunkolade BW, Centola M, et al. Germline mutations in the extracellular domains of the $55 \mathrm{kDa}$ TNF receptor, TNFR1, define a family of dominantly inherited autoinflammatory syndromes. Cell 1999;97:133-44.

22. Todd I, Radford PM, Draper-Morgan KA, McIntosh R, Bainbridge S, Dickinson P, et al. Mutant forms of tumour necrosis factor receptor I that occur in TNF-receptor-associated periodic syndrome retain signalling functions but show abnormal behaviour. Immunology 2004;113:65-79.

23. Siebert S, Fielding CA, Williams BD, Brennan P. Mutation of the extracellular domain of tumour necrosis factor receptor 1 causes reduced NF-kappa B activation due to decreased surface expression. FEBS Lett 2005;579:5193-8.

24. Scallon B, Cai A, Solowski N, Rosenberg A, Song X-Y, Shealy D, et al. Binding and functional comparison of two types of tumor necrosis factor antagonists. J Pharmacol Exp Ther 2001; 301:418-26.

25. Van den Brande JM, Braat H, van den Brink GR, Versteeg HH, Bauer CA, Hoedemaeker I, et al. Infliximab but not etanercept induces apoptosis in lamina propria T-lymphocytes from patients with Crohn's disease. Gastroenterology 2003;124:1774-85.

26. Nedjai B, Hitman GA, Quillinan N, Coughlan RJ, Church L, McDermott MF, et al. Proinflammatory action of the antiinflammatory drug infliximab in tumor necrosis factor receptor-associated periodic syndrome. Arthritis Rheum 2009;60:619-25.

27. Khan P, Weiss M, Imundo LF, Levy DM. Favorable response to high-dose infliximab for refractory childhood uveitis. Ophthalmology 2006;113:860-4.

28. Bohan A, Stracner JE, Austin MC. A "marathon" response to infliximab in dermatomyositis. Ann Rheum Dis 2003;62 Suppl:AB0506.

J Rheumatol 2010;37:8; doi:10.3899/jrheum.091094 